\title{
VALOR HISTÓRICO DE LAS ALTERNANCIAS GRAFÉMICAS EN LOS FONEMAS DEL ORDEN VELAR
}

1. No es la primera vez que recurro al método filológico aludido en el título de este estudio como medio de establecer algunas dataciones en la fonología histórica del español, y no será esta la última ocasión en que me apoye en una tan útil herramienta de trabajo historiográfico, una más - aunque, desde mi punto de vista, primordial- de las que pueden ayudar a adentrarse con solvencia en la diacronía del nivel fonético-fonológico de nuestra lengua ${ }^{1}$. De hecho, la mencionada perspectiva desde hace tiempo ha sido utilizada por no pocos investigadores en determinados aspectos lingüísticos, de tal modo que apenas se sabría nada hoy de la historia del yeísmo si no fuera por el análisis de las confusiones entre las grafías $l l$ y $y$ (con las variantes de una y otra); también se ha atendido con frecuencia a la cuestión ortográfica en lo que se refiere al reajuste de los ant. /s, z, s, $\mathbf{2}$ / en el español central y norteño, así como

\footnotetext{
1 En mayor o menor medida he aplicado el método descrito en este trabajo en mis artículos «Para la historia de la velarización espańola», Archivum, XXVIIXXVIII, 1977-1978, págs. 219-225; «Nueva contribución a la historia del reajuste fonológico del espanol modernox, Cuadernos de Filologia. Studia Linguistica Hispanica, II, 2, 1981, págs. 53-74; «El reajuste fonológico del español moderno en su preciso contexto histórico: sobre la evolución / $/ \mathbf{z}, \mathbf{z} />/ x / »$, Serta Philologica F. Lazaro Carreter, Madrid, Cátedra, 1983, t. I, págs. 219-230; «De los fonemas medievales /S, z/ al interdental fricativo / $\theta /$ del espanol modernox, Philologica Hispaniensia in honorem Manuel Alvar, Madrid, Gredos, t. II, págs. 205-216; "La fonética del español meridional y sus fuentes históricas», Miscel.lania Sanchis Guarner, Valencia, 1984, t. II, págs. 131-137.
}

LXV, 3.0 - 4.0-7 
en las hablas meridionales y americanas. El mismo A. Alonso aduce bastantes datos grafémicos, muchos de ellos de procedencia andaluza, cuando trata de establecer la historia del "seseo" y del "ceceo", no obstante lo cual se siente obligado a advertir:

Es cierto que los filólogos se suelen rendir incondicionalmente ante los cambios de grafías como documento incuestionable de evolución fonética; pero el uso de las grafías requiere crítica igual que cualquier otro de los indicios utilizados en la reconstrucción histórica. $\mathrm{Y}$ no hablo aquí de las frecuentísimas falsas lecturas de los editores modernos, sino de los trueques auténticos de grafías en los documentos antiguos ${ }^{2}$.

Hay que admitir, desde luego, que el linguiista nunca debe desprenderse de un acerado espíritu crítico cualquiera que sea el problema objeto de su investigación, y que la interpretación de las alternancias de los signos gráficos necesita de fuentes adecuadas sobre las que basarse. Dicho esto, hay que comprender las razones que llevaron a A. Alonso a poner en cuarentena los resultados del análisis textual en la culminación y resumen de sus estudios de fonética histórica - la temprana muerte del linguiista navarro imprimió ese carácter a la obra titulada $\mathrm{De}$ la pronunciación medieval a la moderna en español-, entre otras cosas porque la información emanada de un primer criterio filológico contradecía, por su notable disparidad cronológica, las conclusiones extraídas de textos de gramáticos y otros tratadistas, a los que el malogrado maestro concedió mayor veracidad; y también, todo hay que decirlo, porque este autor no manejó una masa suficientemente amplia y diversificada de escritos originales pertenecientes al período en que se desarrollaron todos los procesos fonéticos conducentes al reajuste fonológico del español moderno. Ocurre, finalmente, que A. Alonso solía considerar el cambio fonético como gradual en sí mismo más que en su difusión social, postura que en cierto modo desdibuja el relieve temporal que es capaz de marcar una aproximación filológica a la documentación antigua ${ }^{3}$.

1.1. A nadie se le oculta que, por lo general, la vacilación ortográfica de $l l$ y $y$ está revelando la igualación fonética entre los fonemos preexis-

2 En De la pronunciación medieval a la moderna en español, Madrid, Gredos, 1969 , t. II, pág. 90.

3 Tal es el sentido del siguiente pasaje de su obra ya citada: «Cuando dos grafías, antes usadas sin confusión, empiezan a aparecer confundidas (aparte los casos en que se pueda achacar sólo a la mera semejanza de su dibujo, como en la $t$ y la $c$ medievales), debemos deducir por lo general que ha habido un cambio sensible en la pronunciación. Pero el cambio no tiene que ser necesariamente la igualación de los fonemas concernientes, solo su mayor proximidad acústica* (ibidem). 
tentes $/ \mathrm{l} / \mathrm{y} / \mathrm{y} /$, es decir el yeísmo, en el habla de quien tales «faltas» comete al escribir, tanto da que esta distorsión grafémica se produzca en textos actuales como en los de pasadas sincronías; en realidad, ya he aludido a ello más arriba, es éste el más generoso venero de datos para el seguimiento diacrónico de dicho fenómeno ${ }^{4}$. Tampoco se discute, por ejemplo, que el intercambio de $r$ y $l$, o su pérdida, en la terminación de sílaba interior y final de palabra no descubra una efectiva neutralización de los correspondientes fonemas /-r, -l/ implosivos, y similares verificaciones pueden hacerse sobre otros hechos de fonética vulgar; precisamente, el despojo de corpus andaluces del Medievo y de los siglos XVIXVII me ha permitido plantear en términos radicalmente distintos a los que hasta ahora eran más comúnmente aceptados en dialectología hispánica el tratamiento de la /-s/ implosiva en las hablas del Sur de España, mostrándose mis hallazgos en perfecta consonancia con los notados por P. Boyd-Bowman en fuentes hispanoamericanas del XVI ${ }^{5}$. Pero las cacografías no se refieren únicamente al plano sintagmático, en el que cada caso considerado es de frecuencia variable y de causalidades también múltiples, entre ellas la contextual; por el contrario, la alteración fónica puesta de relieve por un cambio ortográfico más o menos circunstancial es susceptible de remitir a transformaciones en el sistema fonológico, con implicaciones estructurales, por consiguiente.

1.2. Fácil es comprobar, por otro lado, que no son exclusivos del pasado los condicionamientos psicolingüísticos y socioculturales explicativos de hechos textuales similares a los que acabo de aludir, pues su manifestación se da en el presente de muy parecida manera, sobre todo entre hablantes cuyos usos fonéticos suponen un mayor distanciamiento respecto de las normas ortográficas impuestas por la lengua escrita común. Tal cosa se ve a través de los siguientes casos que extraigo de cuatro exámenes realizados en las Pruebas de Selectividad para el ingreso en la Universidad de Sevilla 6: voceo 'voseo', las cuatro veces en que el

4 Son ya numerosos los estudios que proporcionan noticias de esta índole sobre la historia del yeísmo, pero el de carácter más monográfico continúa siendo el de A. Galmés DE FuENTES, «Lle-yeísmo y otras cuestiones linguísticas en un relato morisco del siglo XVII», Estudios dedicados a Menéndez Pidal, Madrid, CSIC, 1956, VII, págs. 273-307.

5 «ateriales para la historia de la aspiración de la /-s/ implosiva en las hablas andaluza», Lingüística Española Actual, 1983, págs. 153-171. Otros muchos datos del mismo tipo, despojados de fuentes andaluzas y americanas, esperan ver la luz en una próxima publicación.

6 De las celebradas en junio de 1983. Guardo fotocopias de los referidos ejercicios, consistentes en el resumen de una conferencia que dicté sobre la historia del 
alumno usó esta palabra, colonisación 'colonización', orientá 'orientada' (ejercicio I); cambios lingüístico, prural 'plural' (dos veces), ciervo 'siervo' (ejercicio II); cosas referente, lo texto juridicos, esto textos (en dos ocasiones), van dirigido, estos texto, juridición 'jurisdicción', conclución 'conclusión' (ejercicio III); relaciones existente, las dos razones más importante, es una de ella 'ellas', Asturia, personas típica; éstos, una vez instalado en América; dos aspectos más importante, Madriz (ejercicio IV).

2. Este modo tan sencillo, e ineludible, de enfocar la fonética evolutiva es perfectamente aplicable a un capítulo de la fonología diacrónica del español, el de la mutación de los antiguos /š, ž/ en el moderno /x/, que cada vez más se presenta sujeto a revisión o, cuando menos, necesitado de nuevas luces que descubran en toda plenitud su verdadero entramado histórico; pero antes de nada es preciso delimitar el alcance de los criterios filológicos y linguísticos con que en esta cuestión debemos movernos. Ha de evitarse, en efecto, el equívoco en el que cae P. BoydBowman cuando, al facilitar interesantísimas noticias documentales sobre este mismo problema fonológico, mete en un solo saco los ejemplos hispanoamericanos galapa 'Xalapa', guannico 'Juanico', enogo 'enojo', guntamente 'juntamente', mégico 'México', trugo 'truxo', digeron 'digeron' (en puridad debería haber puesto 'dixeron', o, con ortografía moderna, 'dijeron'), al lado de gerera 'Herrera', gaser 'hacer', gagays 'hagáis', giso 'hizo', garan 'harán', garta 'harta', todos ellos de mediados del xvI; y estos otros, también americanos, de finales de dicha centuria y comienzos de la siguiente: ygas 'hijas', rigas 'rijas', megor 'mejor', aventagar 'aventajar', gugalla 'jugarla', higitas de azavache 'higuitas...', agilaldo 'aguinaldo', quegar 'quejar', degar 'dejar', yga 'hija', trago 'trajo', megor 'mejor', junto a ajorays 'ahorráis', golgara 'holgara', me guelgo 'me huelgo', rrehistro 'registro', mahestad 'magestad', San Hosed 'San José'. Del referido conjunto de datos saca Boyd-Bowman estas tres enseñanzas, que, en realidad, son partes de una única conclusión: a) por entonces ya se había producido el cambio de $/ \mathrm{s}, \mathrm{z} /$ en $/ \mathrm{x} /$; b) se trata de pruebas de que / $\mathrm{x} /$ se confundía con $/ \mathrm{h} /(<$ lat. /f-/ $)$; ) y de que las correspon-

voseo. A propósito de los casos aqui señalados advertiré que abundan de manera especial en aquellos exámenes reveladores de un muy bajo nivel cultural de quienes los redactaron. Así, dejando de lado el uso de los signos de puntuación -deplorable en los cuatro de referencia-, verifico en ellos los siguientes errores: a pervivido (I); rijen, sintdxticos (III); esperimenta, desgravación por degradación en tres ocasiones, Estremadura, andalucía, sige 'sigue' (IV). 
dientes realizaciones fonéticas a partir de $/ \mathrm{x} / \mathrm{y} / \mathrm{h} /$ habían confluido con el alófono fricativo de $/ \mathrm{g} /{ }^{7}$.

2.1. Este planteamiento -dejada a salvo, sin retórica de ninguna clase, la extraordinaria aportación de Boyd-Bowman al hispanismo- exige, creo, algunas puntualizaciones. En primer lugar, el uso alternativo de $h$ y $x, g, j$ lo único que demuestra palmariamente es que las tres últimas grafías ya no representaban a los fonemas medievales /̌̌, ž/, sino al moderno / $\mathbf{x} /$ de ellos resultante. Sin embargo, se necesitan muchas más claves históricas de las que hasta ahora tenemos en dialectología hispánica antes de intentar precisar el cuándo y el dónde se cumplió el proceso de igualación entre $/ \mathbf{x} / \mathbf{y} / \mathrm{h} /$, allá donde la confluencia fónica tuvo lugar, por aspiración del elemento velar fricativo ${ }^{8}$. $\mathrm{Ni}$ siquiera en dialectología sincrónica existe una puntual descripción de la difusión peninsular del fonema velar $/ \mathbf{x}$ / en sus varias modalidades fonéticas; así, por ejemplo, el mapa 6 del ALPI (abeja) registra en el territorio salmantino un predominio de puntos de $[\mathrm{x}]$ y otros más escasos de $[\mathrm{x}],[\mathrm{h}]$ y $\left[\begin{array}{l}h \\ x\end{array}\right]$, panorama muy similar al que ofrece el espacio abulense; [x] y $[h]$ son las realizaciones de $/ x /$ en Toledo $y$ en Cantabria, con mayor implantación del sonido fricativo en la primera de estas dos provincias y del aspirado en la segunda. Frente a esto, el mapa 13 (ahogarse) señala en Asturias $\left.{ }^{\mathrm{h}} \mathrm{h},{ }^{\mathrm{x}}\right],[\mathrm{h}]$ como resultados de la aspiración del lat. $/ f-/, y[h],[h]$ en Cantabria, con ausencia de $[x]$ en esta circunscripción provincial, sonido que, en cambio, sí le atribuye el mapa de abeja. $\mathrm{Y}$, todavía, si se comparan los mapas 6 (abeja) y 11 (aguijón) se notará

7 P. Boyd-Bowman, "A sample of sixteenth century 'Caribbean' Spanish phonology», 1974 Colloquium on Spanish and Portuguese Linguistics, Washington, Georgetown University Press, 1975, págs. 2, 8.

8 Aunque por lo general utilizo aquí el símbolo /h/, fonológico, lo hago con la finalidad de unificar referencias fonético-fonológicas de los distintos estudios que debo citar, y para simplificar mi exposición. No me pronuncio, pues, sobre el carácter fonológico o meramente fonético de la aspiración procedente del lat. /f $/$, ni, en su caso, sobre las relaciones sistemáticas que le serían propias. A este respecto, E. Alarcos Llorach da [h] como variante de /f/ en el sistema fonologico alfonsí y medieval, $y$, para la época del reajuste, habla de alos dos fonemas /f/ y /h/ toledanos», advirtiendo que en el español moderno «queda sólo /f/, salvo en zonas marginales, donde ha perdurado /h/ (confluyendo con otros fonemas) $)$ : Fonologia española, Madrid, Gredos, 1968, 4.` ed., págs. 264, 268. Similar punto de vista mantiene este autor en una investigación más reciente, con la particularidad de que en ella se refiere también a «los restos de la medieval / $h$ / castellana», mientras que en la obra precitada consideraba que en el periodo medieval de lo que se trataba era de una variante alofónica de /f/: «Más sobre vocales andaluzas», Philologica hispaniensia in honorem Manuel Alvar, I, Madrid, Gredos, 1983, págs. 49-55. 
que mientras el primero da [h] para el punto 401 de Cantabria, [x] para el 427 de Burgos y [h] para el 466 de Toledo, el segundo atestigua, respectivamente, $\left[\begin{array}{l}\mathrm{h} \\ \mathrm{x}\end{array}\right],[\mathrm{x}] \mathrm{y}[\mathrm{x}]^{9}$.

Entiendo yo que aún estaría más fuera de lugar el afirmar que en los dominios en que existía la aspiración procedente del lat. /f-/ fue tam-

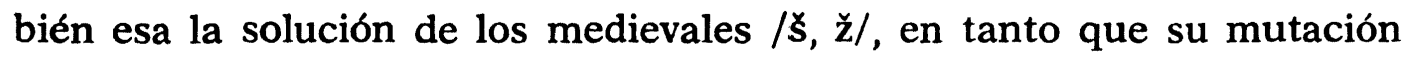
habría consistido en / $x$ / sólo en aquellas áreas que al finalizar la Edad Media habían perdido ya dicha aspiración. A no dudarlo, pues, el cambio $/ \check{s}, \check{z} />/ x /$ se verificó en todas partes, aunque la fricación velar pudiera convertirse en aspiración donde ésta, originada en /f-/ y/o en /-s/ implosiva, preexistía. No es fácil determinar el momento en que se hizo efectiva la mencionada confusión fonética, entre otras cosas porque en ella medió, al menos en ciertos sitios, un proceso bastante generalizado de relajamientos consonánticos que también afectó al fonema $/ \mathbf{x} /$, convirtiendo su realización fónica de fricativa en aspirada.

Prueba de lo que acabo de decir es, a mi entender, el hecho de que la aspiración de $/ x$ / se halle intensamente difundida en buena parte de Andalucía, mientras que una apreciable porción de este ámbito meridional desconoce la que tiene como ascendiente etimológico el lat. /f-/; incluso sucede que la Andalucía que mantiene el estadio evolutivo $/ \mathrm{h} /<$ /f-/ lo hace en un medio casi estrictamente rural y de un modo cada vez más esporádico y lexicalizado, pues, en resumidas cuentas, este fenómeno se encuentra hoy en franca regresión. Sumamente ilustrativa es a este propósito la consideración del mapa $1715 \mathrm{del} A L E A$ («área de aspiración o fricación velar de la $h<$ étimon con $F-»)$, que proporciona las siguientes enseñanzas: $1^{\circ}$ ) la aspiración, en efecto, se localiza preferentemente en núcleos rurales, con tanta mayor fuerza cuanto menor es el nivel cultural del informante; $2 .^{\circ}$ ) particularmente se refleja este determinismo sociológico entre hablantes urbanos, y aun aquí habría que tener en cuenta el flujo migratorio desde el campo hacia la ciudad; $3 .^{\circ}$ aunque la lexicalización es más propia, pero no exclusiva, de zonas de Andalucía oriental, otros muchos puntos de toda la región descubren la alternancia del sonido aspirado y su ausencia ${ }^{10}$. El mapa 1716 ( «realizaciones fonéticas del fonema castellano $/ x / »)$ muestra un gran polimorfismo fonético de $/ x /, y$, lo que ahora más me interesa destacar, se ve también en él que, si bien el alófono fricativo de este fonema se centra

\footnotetext{
- Atlas Lingülistico de la Península Ibérica, I, Madrid, CSIC, 1962.

10 M. Alvar, con la colaboración de A. Llorente y G. SALVADOR, Atlas Lingüistico y Etnografico de Andalucia, Universidad de Granada, 1961-1973.
} 
sobre todo en la Andalucía que no aspira /f-/, sin embargo, en ella se verifican asimismo con bastante frecuencia diversos grados de aspiraciones de $/ x /$, lo que demuestra que el influjo ejercido por la existencia previa de una $/ \mathrm{h} / \mathrm{y}$ la tendencia al relajamiento consonántico han podido actuar de consuno en determinadas hablas, pero que no son condicionamientos que se exijan mutuamente, siendo el segundo capaz de propiciar dicha alteración fonética sin el concurso del primer factor. Esto se ve con meridiana claridad a través de la consideración de hablas distintas a las andaluzas, como las murcianas, y de manera muy especial con los datos que el $A L E A N R$ facilita del dominio que describe, en el cual, habiéndose conservado invariablemente la /f-/ en reliquias del antiguo dialecto aragonés, se encuentran puntos donde / $\mathrm{x} /$ se hace $\left[\begin{array}{l}\mathrm{h} \\ \mathrm{x}\end{array}\right]$, concretamente en dos de Teruel y en otros tantos de Navarra ${ }^{11}$.

2.2. Ni que decir tiene que el deterioro de la situación dialectal concerniente a la aspiración de /f-/ en Andalucía viene de muy atrás, y su arranque sin duda se localiza en los últimos años del siglo Xvi y primeros del XVII, con cronología similar, pues, a la del resto de la España que aspiraba. A vueltas con la aspiración debía hallarse el relajamiento articulatorio de $/ x /$, a tenor de aquella famosa advertencia que en el Buscón recibe Pablos de su antiguo condiscípulo de Alcalá nada más llegar a Sevilla: "haga vucé de las $g, h, \mathrm{y}$ de las $h, g$. Diga conmigo: gerida, mogino, jumo, paheria, mohar, habali y harro de vinon, palabras de Quevedo que, sin embargo, no es seguro que deban entenderse demasiado al pie de la letra, ni siquiera en la particular connotación sociolingüística que encierran ${ }^{12}$. Más tarde, a comienzos del XIX, un maestro

11 M. Alvar, con la colaboración de A. Llorente, T. Buesa y Elena Alvar, Atlas Lingüístico y Etnográfico de Aragón, Navarra y Rioja, Madrid, La Muralla, 1979. 1984. Recojo esta pronunciación semiaspirada para el caso aragonés con los términos judias, tijeras, esqueje, recogedor, tejas, tejado, pajuzo, teja de río y hendrija (mapas $302-305,341,342,901,920,921,932,935,937)$, y para el navarro con tijeras y raja (mapas 341,937 ).

12 Esta cita del Buscón admite, en efecto, diversas interpretaciones, una de las cuales, y la más obvia, es la de tomarla como prueba de la existencia del fonema velar / $\mathbf{x}$ / en la Sevilla de los comienzos del siglo xvir, otra la de admitir que sustenta históricamente la igualación fonética $/ x /=/ h /, y$, por último, la de juzgar a través de ella que este hecho lingǘstico era ya exclusivo de un hablar marginal, lo que concedería mayor antiguiedad a los dos puntos anteriores. Hay que tener en cuenta, sin embargo, que Quevedo no era andaluz y, en cualquier caso, que puede estar recurriendo a un tópico literario. Es preciso considerar, además, que los poetas sevillanos de la época aún practicaban la aspiración de /f-/ en sus versos, $y$, finalmente, que años después de escribir Quevedo la mencionada obra, un andaluz, el jesuita jiennense Juan Villar afirmaba, en 1651, que ese «vicio», el referido por la 
de primeras letras natural de Cádiz, de nombre Antonio Balbina Lozano, por un lado venía a decir que la aspiración de /f-/ existía en tierras de Andalucía occidental, y, por otro, significaba que la acción de la escuela se encaminaba a combatirla:

MaESTRo. La $h$ es letra semivocal, no es aspiración, y sin ella no nos entenderíamos en la escritura.

Discfpulo. Quisiera saber por qué.

Maestro. Aspiración, la acción de aspirar. También es la fuerza con que se pronuncian las vocales, que en algunas lenguas se denotan con la letra $h, y$ en castellano sólo en algunas dicciones. Ello es una aspiración tonta, y gran disparate escribir comprehender y pronunciar comprejender, hilo jilo, horno jorno. Para establecer esta regla andaluza se había de decir ¿qué jora es?; el jemisferio ${ }^{13 .}$

La circunstancia de que en cierto momento empiecen a intercambiarse las grafías $x, g, j$ con $h$ lo único que asegura, pues, es la presencia del nuevo fonema / $\mathrm{x}$ / en la norma de un indeterminado número de hablantes, y no que se hubiera igualado fonéticamente con /h/ ( $<$ lat. /f-/), fenómeno éste, el de la equiparación $/ \mathrm{x} /=/ \mathrm{h} /$, que resulta muy difícil de ser fijado en su exacta dimensión histórica. En primer lugar porque, ya lo hemos visto, la actual sincronía pone de relieve que tanto / $h /$ puede hacerse [x] como / $\mathrm{x} /$ pronunciarse [h], y por el solo análisis de las grafías no cabe discernir con seguridad si ha habido igualación y en qué dirección se haya producido: efectivamente, hay textos de un único dominio en los que lo mismo alternan $h$ y $x, g, j$ para ambos fonemas, mientras que otros hacen exclusivas $g \circ j$ para representar esporádicamente en la escritura a $/ h /$, sin que $h$ se emplee en ellos como signo ortográfico de $/ x /(</ \xi, z /)$. En segundo lugar, porque semejantes confusiones de grafías se ocasionan también en corpus localizados en áreas en las que la aspiración de /f-/ o nunca se había conocido o había desaparecido en

confusión ortográfica de $h$ con $x, g$, se extendía por toda Andalucía occidental: cf. mi artículo *La fonética del español meridional y sus fuentes históricas», $\S 1.1$

13 Ms. 331/130 de la Biblioteca Universitaria de Sevilla, que se escribió en los años de la Guerra de la Independencia (fol. 10v); sobre este texto manuscrito ha publicado M. Alvarez Garctı el estudio «Sobre la enseñanza de la lengua española en Andalucía a principios del siglo XIX», Archivo Hispalense, núm. 203, 1984, páginas 165-177. El no tener clara la distinción entre letra y sonido ha hecho que este maestro, decidido defensor de las normas emanadas de la Real Academia Española. traslade una inexistente pronunciación aspirada a comprehender, hora y hemisferio. Con este hecho se relaciona de alguna manera la explicación del andaluz jordenança 'hordenança, ordenança' de 1479 que aduzco en «El reajuste fonológico del español moderno en su preciso contexto histórico: sobre la evolución $/ \mathbf{s}, \mathbf{z} />/ x / »$, pág. 228. Véase también lo que se dice más abajo, en la nota 15. 
el tránsito de la Edad Media a la Moderna. Pretender sacar conclusiones que establezcan matices fonético-fonológicos a partir de confusiones grafémicas que operan en los términos ya descritos sería tanto como promover una casuística inverificable $y$, casi inevitablemente, gratuita.

Si los precitados hechos ortográficos tuvieron lugar fue, sencillamen-

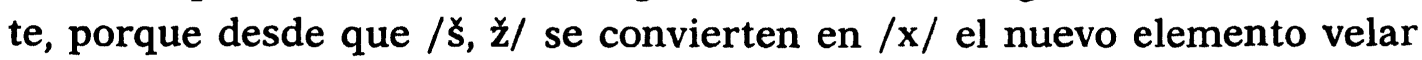
fricativo pasa a relacionarse articulatoria y acústicamente con el aspirado / $/$ / en las hablas poseedoras de esta otra unidad fónica, o en aquellos hablantes-escribientes que en su hablar materno no contaban con la aspiración, pero sabían de su existencia en otros dialectos del español y que la grafía correspondiente era $h$. Esto es lo que condicionó el uso de h por $x, g, j, \mathrm{y}$ a la inversa, "faltas» sueltas cometidas de modo inconsciente por parte de quien escribía - lo que a no dudarlo es el supuesto más generalizable-, o bien con la decidida intención de conseguir así efectos expresivos o de otro tipo, propios de la creación literaria.

En cualquier caso, preciso será no perder de vista en toda esta cuestión una importante referencia cronológica, en el sentido de que mientras coexisten en español dos normas fonéticas bien diferenciadas - la de quienes aspiran / $\mathrm{f}-/ \mathrm{y}$ la de aquellos hablantes en los que a la aspiración se corresponde el cero fonético- con similar grado de prestigio sociocultural, son posibles en la escritura los mencionados cambios recíprocos de $h$ y $x, g, j$, todavía más teniendo en cuenta que durante un cierto tiempo, aproximadamente en los dos primeros tercios del XVI, la primacía en este terreno recayó sobre el habla toledana, aspiradora como se sabe. Pero desde el instante en que la modalidad lingüística que mantenía la /h/ se degrada para convertirse en hecho de habla rural o vulgar - cosa que empieza a ser una amplia realidad a mediados del xVII-, ya no podrá traducirse gráficamente la aspiración de / $\mathrm{x} /$ si no es por medio de la elisión pura y simple de $x, g, j, y$ el sonido aspirado procedente de /f-/ o de /-s/ tendrá que grafiarse con alguno de estos tres signos ${ }^{14}$.

Es lo que, por lo que concierne a $/ \mathrm{h} /$, se verificará en los sainetes de don Ramón de la Cruz, que escribe jacienda, jecho, jiziera, jaze, jaremoz,

14 Sobre todo con $g$ o $j$, que eran los usuales a comienzo de palabra. En lo que a la lengua literaria se refiere, hay que recordar que Garcilaso, toledano, mantiene la aspiración, igual que el salmantino fray Luis de León o, en el último tercio del siglo XVI, los poetas sevillanos del grupo herreriano, y lo mismo hacía el también hispalense Rioja hacia el 1620; poco después, en 1625, el extremeño Gonzalo Correas era aún acérrimo defensor de la modalidad aspiradora. Pero las cosas no tardarían en cambiar al imponerse definitivamente como norma culta única, al menos en este preciso aspecto linguístico, el habla de la región de Madrid, sede de la Corte. 
jacer (por hacer, etc), jembra 'hembra' 15; lo mismo se comprobará más tarde en los relatos santanderinos de Pereda o en la recepción académica de andalucismos como jamelgo y juerga ${ }^{16}$, $u$ hoy en tantos catastros municipales de Andalucía occidental, donde abundan los ejemplos de idéntica índole ${ }^{17}$. Igual resultado ortográfico se produce a propósito de la aspiración de /-s/ en La infancia de Jesu-Christo, obrita impresa en Málaga en la primera mitad del xviII, que proporciona registros como los jojos 'los ojos' o las jorejas 'las orejas', en los que con la $j$ - se quiere plasmar la aspiración de la sibilante final del artículo, al lado de casos como jecho o jambre. Antes, la $h$ no sólo representaba la aspiración de /f-/ y sustituía ocasionalmente a $x, g$, $j$, sino que, aunque con no demasiada frecuencia, podía señalar la del fonema /s/, implosivo o no. Del año 1602 es la documentación onubense de un hurtos 'surtos' que he aducido en otra parte ${ }^{18}$, y similar atestiguación, ahora para /-s/, se halla en texto chileno de 1577-89: "el oficio de pertiguero y el servir de acólitos háceloh ( $\mathrm{sic}$ ) los que son de corona y grados» ${ }^{19}$.

2.3. Hay que precisar ahora una última cuestión, en la cual se entrecruzan aspectos de historia de la ortografía española y de fonética evolutiva. A saber, el que en fuentes hispanoamericanas aparezcan con alguna frecuencia formas como galapa 'Xalapa', enogo 'enojo' o guntamente 'juntamente' no quiere decir, como pretende Boyd-Bowman, que

15 Recojo estos ejemplos sólo en el titulado Los gitanos festivos, escrito en 1780: Tres obras inéditas de don Ramón de la Cruz, edición a cargo de Edward V. Coughlin y otros, Barcelona, Puvill Editor, 1979, págs. 64, 70, 71, 73. Recordando lo dicho en la nota 13, añadiré que Cruz escribe también jabemos 'habemos' con falsa aspiración de una inexistente /f-/ etimológica (pág. 64), llevado del «fetichismo de la letrax, expresión feliz que A. Rosenblat aplicó a otra cuestión ortográfica en el ámbito mejicano: Fetichismo de la letra, Caracas, 1963. Otros casos de $j$ por $h$ en obras de este dramaturgo: juye en Las castañeras picadas; juera 'fuera', ajuera 'afuera', juerza 'fuerza', en Manolo, tragedia para reír o sainete para llorar: Sainetes, Madrid, Compañía Ibero-Americana de Publicaciones, s. a., págs. 18, 20, 132.

16 Andalucismos admitidos por la Academia, respectivamente, en 1884 y 1899: J. Corominas, con la colaboración de José A. Pascual, Diccionario crítico etimológico castellano e hispánico, Madrid, Gredos, 1980 y sigs. [citado $D E C H$ ], s. vv. hambre, holgar.

17 Cuatrojenales 'Cuatro Henares', Valjondo 'Valle Hondo' (en las hojas catastrales de Guadalcanal); Laguna del Jorcón 'del Horcón' (Almonte); Bujeo del Cuervo 'Buhedo', La Jarda, La Jardilla ant. 'harda, ardilla' (Jerez de la Frontera); La Jesa 'dehesa' (Arahal); Bujeos, Bujetllos 'buhedo, buhedillos' (Ubrique); Joyanca 'Hoyanca' (Estepa).

18 En mis «Materiales para la historia de la aspiración de la /-s/ implosiva en las hablas andaluzas», pág. 167.

19 P. Boyd-Bowman, Léxico hispanoamericano del siglo XVI, s. v. acólito. Sin duda habrá que leer hácenloh 'hácenlos'. 
su $g$ tenga igual referencia fonética que la de gaser 'hacer' o garta 'harta'; la simple coincidencia grafémica, que de ningún modo constituye una novedad, no basta para sacar semejante conclusión, como ya he tenido oportunidad de adelantar en un estudio muy reciente ${ }^{20}$. Puedo añadir aquí nuevas documentaciones que, por su amplitud cronológica y diversidad geográfica, son suficientemente demostrativas de que no puede dárseles la interpretación que el citado hispanista norteamericano atribuye a idénticos casos grafémicos del español del Nuevo Mundo. Así, los andaluces coga 'coja' (a. 1345) ${ }^{21}$; gur 'jur, juro (derecho que se tiene sobre algo)' (a. 1375); mongas 'monjas' (años 1376, 1378) 22; Argonilla 'Arjonilla' (a. 1485) ${ }^{23}$. O los aragoneses rega 'reja', tinagas 'tinajas' franga 'franja', agugas 'agujas', cerrogo 'cerrojo' (a. 1484) ${ }^{24}$; gardín 'jardín', degar 'dejar', degando 'dejando', tega 'teja', tegado 'tejado', tegarlo 'tejarlo', atagos 'atajos', degarlo 'dejarlo' (a. 1591) ${ }^{25}$. Más ejemplos de esta clase podría traer a colación, pero creo que ya son bastantes para aclarar que estamos, nada más y nada menos, ante una verificación tan sencilla como ésta: si es cierto que en la ortografía del castellano culto se prefirió el empleo de $g \mathrm{y}$, menos, de $j$ como grafías de $/ \check{z} /$, luego también de su heredero $/ x /$, ante /e, $i /$, especializando la $j$ como representación de este

20 «El reajuste fonológico del español moderno en su preciso contexto histórico...», págs. 226-228, donde doy testimonios andaluces, murcianos y aragoneses de igual configuración grafémica (regolla 'rejola', Guan 'Juan', megor 'mejor', etc.), con la particularidad de que algunos de los territorios a los que pertenecen las fuentes de estos despojos documentales no han conocido el cambio lat. $/ \mathrm{f}-/>/ \mathrm{h} /$.

21 Cf. M. Luisa Pardo Rodrfguez, Huelva y Gibraleón (1282-1495). Documentos para su historia, Huelva, 1980, doc. 20, pág. 88. Hay dos registros de la forma coga.

2 Cf. M." Asunción Vilaplana, La colección diplomática de Santa Clara de Moguer, 1280-1483, Publicaciones de la Universidad de Sevilla, 1975, docs. 72, 73, 75; págs. $218,219,224$. Sólo una vez hallo el arcaico gur con esta grafía $g$ («non desapoderamos nos de todo el gur e el poder e el derechow); en todos los documentos anteriores al 72 siempre se lee $j u r$.

23 Cf. M. Acín Almansa, Ronda y su Serranía en tiempo de los Reyes Católicos, Málaga, 1979, pág. 549. Argonilla convive con Arjonilla en el mismo párrafo. El texto de este repartimiento nos ha llegado en copia manuscrita de 1655 .

24 C. J. Writuin, «Un inventario turolense de 1484: los Sánchez Muñoz, herederos del papa Clemente VIII», Archivo de Filología Aragonesa, XVIII-XIX, 1976, págs. 198, 201, 202, 205.

25 Cf. A. SAN VICENTE, Monumentos diplomáticos sobre los edificios fundacionales de la Universidad de Zaragoza y sus constructores, Zaragoza, Institución «Fernando el Católico», 1981, págs. 224225. Algunos de estos ejemplos se repiten con reiteración; de hecho, en el texto citado sólo se emplea el signo g para grafiar lo que fueron los medievales $/ \xi, \xi /$, con las únicas excepciones de un tejado y un janero 'enero' dialectal; y $g$ también se usa como grafía simple de /g/ ante /e, i/: sigiente, largeça, sogetas 'soguetas'. Todo esto no hace sino corroborar el deficiente nivel cultural del documento en cuestión, en consonancia con otros rasgos linguirsticos vulgares que en él se encuentran. 
fonema seguido de / $a, o, u /$, no lo es menos que entre usuarios menos selectos de la lengua escrita se tendió con relativa facilidad a una simplificación grafémica ${ }^{26}$. E intuyo que no será ocioso reproducir aquí la advertencia que don Francisco Codera hacía a propósito del reiterado registro de yga 'hija' en anotaciones del concejo de Fonz de los años 1599 y 1600: «al reirnos del apuntamiento verdadero o supuesto de aquel que puso en un cuaderno de notas 'lista de los ygos que voy tubiendo; el primer ygo que tube fue una yga', ponemos de manifiesto nuestra ignorancia, de la que podría burlarse el burlador» ${ }^{27}$.

La existencia de grafías tales como enogo y gaser tampoco permite sostener que indiquen la confusión fonética de $/ \mathrm{x} / \mathrm{y} / \mathrm{h} /$ con el alófono fricativo del también fonema velar /g/, pues en contra de este supuesto abogan los argumentos filológicos que acabo de esbozar. Pero hay, asimismo, una evidencia linguística que impide hablar, por referencia al español de mediados del XVI, de un anew fricative allophone of $/ g / »$, evidencia que la dan ya los numerosos casos de pérdida de consonantes sonoras intervocálicas en los materiales que el propio Boyd-Bowman maneja: perdio 'perdido', plea 'plega', que 'quede', to y tos 'todo, todos', ahua 'agua', arcauz 'arcabuz', da 'daga', calsaos 'calzados', prozé 'procede', deseá 'deseada', consía 'consiga', Beatriz e Barrasa 'Beatriz de Barrasa' ${ }^{28}$. Si se suma a esto el que dichos datos estén perfectamente atestiguados en fuentes hispánicas peninsulares desde la Edad Media, y algunos de ellos con bastante frecuencia a partir de la segunda mitad del siglo XIv ${ }^{29}$, será fácil entender que ese «nuevo» alófono fricativo de /g/

26 Esto es válido también para / $\$$ / desde el momento en que su realización se confunde con la del correlato sonoro; de todos modos, incluso entre autores pertenecientes a la elite cultural se dan esporádicos registros ortográficos de este tipo, así en un Sebastián de Horozco, que en 1565 ponía froga por foria: Relaciones históricas toledanas, introducción y transcripción por J. Weiner, Toledo, 1981, pág. 179. Y en el manuscrito de la Segunda parte del entremés de Diego Moreno, de Quevedo, su editor ha señalado los eerrores» este guego 'este juego' y Gustina 'Justina': FrancIsco DE QUEVEDO, Obra poética, edición a cargo de José Manuel Blecua, Madrid, Castalia, 1981, IV, pág. 47.

27 En las Relecciones del Archivo de Filología Aragonesa, XXXII-XXXIII, 1983. página 375.

28 Art. cit., págs. 2, 10-11. Las fechas de estos testimonios abarcan desde los años cincuenta del siglo xvi hasta el 1617. Aunque no con la misma frecuencia, tal vez, en otras fuentes de Indias que Boyd-Bowman extracta también se atestigua este fenómeno, así ocurre con los ejemplos mejicanos ca 'cada' y ahuelos 'abuelos' de mediados de esta centuria: Léxico hispanoamericano del siglo XVI, s. vv. abuelo, zumbre.

29 En «La fonética del español meridional y sus fuentes históricas» aduzco formas medievales que conciernen al debilitamiento de las consonantes sonoras intervocálicas. 
no lo era tanto; piénsese, además, que, según Alarcos Llorach, en la época alfonsí «tampoco debía de ser muy clara la distinción entre las dos series sonoras: seguramente $/ \mathrm{d} / \mathrm{y} / \mathrm{g} /$ ya presentaban variación ( $\mathrm{y}$ en ellas habían confluido los escasos restos de /d/ y /g/ intervocálicas latinas)» ${ }^{30}$, es decir, que /g/ tenía ya en la decimotercera centuria como variantes combinatorias un alófono oclusivo y otro fricativo.

Ello no implica, desde luego, que entre 1550 y 1600, aproximadamente, no pudiera haber hablantes que de modo constante o en polimorfismo igualaran $/ \mathbf{x} /$ con $/ \mathrm{h} /$, pues no es impensable que la alternancia de $h$ con $x, g, j$ en ciertos casos signifique tal cosa ${ }^{31}$. Tampoco podría negarse por principio que se hubiera llegado a su confusión -que, sin duda, habría de ser polimórfica - con un alófono de $/ \mathrm{g} /$, sólo que, de una parte, es necesario extremar la cautela en lo que a esta cuestión concierne, y, de otra, es claro que no se han dado los adecuados argumentos grafémicos que permitan afirmarlo ${ }^{32}$. El paso de $/ \mathrm{x} / \mathrm{a} / \mathrm{g} / \mathrm{se}$ da hoy en sitios aislados con lexicalización, lo que ocurre, por ejemplo, con los aragoneses borraga 'borraja' o güina 'juina (fuina, garduña)' ${ }^{33}$, en ocasiones como resultado de asimilación o disimilación de velar a velar, así en guinjolero 'jinjolero (azufaifo)', y en el caso inverso de jajo 'gajo', donde /g/ ha cambiado a $/ \mathrm{x} /{ }^{34}$. El fenómeno recibe, por supuesto, aceptación mucho mayor en

30 Fonología española, pág. 266. Más adelante se refiere Alarcos a «las dos series antiguas de oclusivas», entre las que pone /b, d, g/, y de africativas» (entre las cuales figuran $/ 0, a, 8 /)$, que en el sistema reajustado de los siglos XVI y XVII "quedaban fundidas en una sola con las variaciones alofónicas oclusiva y fricativa (página 269). Ello no obstante, este estudioso se inclinó por proponer para el sistema del castellano alfonsí y medieval los fonemas /b, d, g/ entre los oclusivos sonoros (pág. 265). Una vez más, a la pregunta de cuándo y cómo, sociológica y geográficamente, se prolujo la mutación fonológica en este concreto punto, sólo podrá responderse fehacientemente mediante el despojo documental.

31 Una forma como de 'dexe, deje', registro panameño de 1592 (P. Boyd-Bowman, art. cit., pág. 8), parece reflejar, si se trata de una lectura correcta, una fuerte aspiración, o el cero fonético, del fonema velar fricativo /x/. Esto aparte de que testimonios como el del P. Juan Villar muestran que el relajamiento del correspondiente sonido era un hecho en amplias zonas de Andalucía occidental.

$32 \mathrm{Ni}$ siquiera tiene por qué darse siempre la sustitución con el alofono fricativo de $/ g /$, puesto que, sobre todo tras pausa o consonante interrupta, también puede entrar en danza el oclusivo.

33 ALEANR, mapa 474 con muchos puntos de güina en las provincias de Teruel y Zaragoza, donde en menor proporción existen otros de juina; el 322 recoge borraga en dos localidades navarras.

34 En el DRAE se registran las variantes guinja, guinjo, guinjol, guinjolero y jinja, jinjo, jinjol, jinjolero para los significados 'azufaifa' y 'azufaifo'; en el DECH se da el doblete guinjolero-jinjolero, con la advertencia, que no comparto, de que en las formas con gu- ha habido influjo analógico de guinda (s. v. azufaifa). Aunque los puntos encuestados para el $A L E A N R$ no descubren ninguno de estos términos con gu-, sin embargo, no son del todo desconocidos en Aragón, pues en el 
hablas, como las andaluzas, que acusan intensamente la tendencia al relajamiento consonántico, pues, a mi modo de ver, de esto es precisamente de lo que se trata, visto que sea en la Andalucía que aspira / $\mathbf{x}$ / donde también se localizan los puntos de pronunciación [g] de este fonema ${ }^{35}$. En conclusión, hay que pensar bien las cosas antes de sacar consecuencias fonético-fonológicas de tal entidad de una mera apariencia ortográfica, que no constituye singularidad alguna si se la considera en el marco general de la historia de la ortografía del castellano y de otros dialectos hispánicos, máxime teniendo en cuenta que semejante afirmación afecta a una tan compleja realidad dialectológica, incluso para lo que a la contemporánea sincronía dialectal del español atañe.

3. Existen, sin embargo, pruebas grafémicas de una gran transparencia en lo que toca al descubrimiento de modos de pronunciación innovadores en un castellano a punto de convertirse en español, lengua nacional. Ciertamente, el sistema fonológico medieval se hace más universal con el cambio que en él se opera, puesto que afectará de igual modo a extensas áreas linguísticas antes patrimoniales de los antiguos dialectos leonés y aragonés; incluso se dará lugar a interferencias fonéticas de importancia en el dominio gallego, en menor grado en el catalán, y hasta en una lengua no románica, pero sí hispánica, como es el vasco ${ }^{36}$. Y, todavía hay más, mientras el nuevo orden de cosas fonológico está cobrando carta de naturaleza, se expanden hechos de diferenciación dialectal por el Mediodía peninsular, Canarias y allende el Atlántico, y no cabe duda que supondría un decisivo enriquecimiento para el español moderno el conseguir conjugar con singular éxito la diversificación de normas regionales con la unidad idiomática. De las aludidas evidencias ortográficas me ocuparé a continuación pormenorizadamente.

habla de Magallón sí es usual la voz guinjol 'azufaifa', frecuentemente realizada grínjol; en cuanto a jajo 'gajo', su difusión es muy amplia por tierras aragonesas.

35 Véase el ya citado mapa 1716 del ALEA. Son menos, en cambio, los puntos en que /h/ $(<$ lat. /f-/) se convierte en [g]; concretamente, dos hay señalados en el mapa 1715. El resultado inverso es también posible en Andalucía, con paso de /g/ a / $\mathbf{x}$ / de realización aspirada; así en el gaditano sanjuán 'zaguán', que parece reflejar una etimología popular. Por el contrario, el habla albaceteña de La Roda, donde el relajamiento articulatorio es mucho menos sensible que en el dialecto andaluz, no conoce este fenómeno, y es de observar que $/ x /$ sólo se articula como aspirada entre los hablantes más rústicos e incultos: T. ChAOON BerRUga, El habla de La Roda de la Mancha, Albacete, 1981, págs. 336-337.

36 El gallego sufrió el fenómeno de la «gueada» y de la «geada», al que más abajo habré de referirme con más detalle; el catalán recibirá castellanismos con su fonema $/ x /$ convertido en $/ k /$, y a bilingüismo se deberá la presencia en hablas vasco-spañolas del fonema $/ x /$, que falta en el espacio vasco-francés. 
3.1. En cuanto al empleo de $h$ por $x g$, $j$, los trabajos que más arriba cito ${ }^{37}$ contienen los siguientes casos: un hentil 'gentil' anterior a 1519, un murciano Huan 'Juan' atestiguado en 1568 y el gongorino paharito 'paxarito, pajarito' de 1600; pero otros testimonios del género me han facilitado mis lecturas de los dos últimos años. El primer caso, por orden cronológico, figura en una de las entradas del diccionario etimológico de Corominas, concretamente en un salmantino harpillera de 1505, al que documentalmente se corresponde un zaragozano sarpillera de 1497; pues bien, el hecho de que el filólogo catalán no tuviera ideas más puestas al día de la manera en que el reajuste fonológico del español pudo desarrollarse - hay que decir, con todo, que no es el único hispanista dominado por esta particular desinformación- lo llevó a afirmar: «La idea insinuada por Castro de que sarpillera pasara a xarpillera, jarpillera, y después se tomara esta $j$ - por una $h$-aspirada, no es posible, teniendo en cuenta que la forma con $h$ - ya aparece en 1505 , cuando la $x$ todavía no se confundía con $j-{ }^{38}$. Y, sin embargo, no sólo se igualaban $x$ y $j(/ \zeta /=/ \check{z} /)$ en muchos textos de la época, y aún anteriores, sino que entre ciertos hablantes se había llegado a la velarización de este par fonológico. Por las mismas razones, tampoco le sacará Corominas todo el jugo histórico que tiene a la datación hispanoamericana de bujería 'bufería, buhería' (cf. § 3.2).

A pesar de las aportaciones que en esta dirección se han dado en los últimos años, estamos en el inicio de una tarea que se adivina prometedora y apasionante. Un ejemplo probatorio de lo que digo es el hecho de que R. Lapesa cite sólo el arriba aducido paharito ${ }^{39}$ y que en la misma composición burlesca Góngora escribiera vieho 'viejo' pocos versos antes, sin que se comprenda muy bien cómo mediante una pronunciación

37 Véase la nota 1. Estos datos no eran conocidos en su conjunto por los historiadores de la lengua española, pero sí algunos de ellos en forma aislada, y me refiero tanto a los casos de $h$ por $x, g, j$ como a los usos grafémicos contrarios. No reproduciré aquí comentarios e interpretaciones que en su lugar he dado ya.

$38 \mathrm{DECH}$, s. v. harpillera. La intuición de Américo Castro, historiador y filólogo, se ha plasmado aquí en un notable acierto, pues de las variantes hispánicas con $s$ - o con $x$ - de esta palabra sólo se ha podido pasar a harpillera a través de un proceso de velarización, como en jabón o jimio. Por otro lado, en el Cancionero de Pedro del Pozo, manuscrito en la misma Salamanca el año 1545, se descubre otro caso de pronunciación velar ortográficamente representada con una grafía antes signo de fonema palatal (caso de aljadi por alhadi). La primera fase del mencionado cambio fonético (sarpillera $>$ xarpillera) es también idéntica a la que se verifica de servilla 'zapatilla' a xervilla, variantes que abundan en fuentes de los siglos XvI-XvII (DECH, s. v. siervo).

39 R. LAPEsA, Historia de la lengua española, Madrid, Gredos, 1981, 9.• ed., página 380 . 
velar, fricativa o aspirada, se podía estar «imitando el habla infantil» ${ }^{40}$. También R. Jammes dice que se trata de «lenguaje aniñado», pero lo cierto es que todo lo que en esta letrilla se conceptúa como modismo infantil (cualto 'cuarto', pata 'plata', tato 'trato', etc.) está perfectamente documentado en fuentes andaluzas en las que ninguna cabida tiene el juego literario, y todo ello se verifica hoy en diferentes hablas hispánicas. Hay que ver en esto la manifestación de un tópico de la literatura española de los siglos XVI al XVIII, consistente en la acumulación -que por ser exagerada se convierte en estereotipo- de rasgos de fuerte connotación vulgar o rústica, regionalismos linguísticos por lo general, puestos en boca de individuos pertenecientes a grupos marginales con objeto de provocar la hilaridad del lector o del espectador. La finalidad satírica es clara en el empleo que Quevedo hace de horoba 'joroba' hacia 1627, en "Cómo ha de ser el privado»:

Haré lo que un cortesano que a una señora ha hallado jugando con su marido; par de monstruos nunca oído, ella vieja, él corcovado, con unos tantos de huesos. $Y$ viendo que naipes daban, preguntó lo que jugaban, y el horoba dijo: «Besos» 41 .

Corominas no documenta joroba hasta el Diccionario de Autoridades, y asegura que no era palabra corriente a principios del XVII, aunque piensa que «la pronunciación antigua fue horoba con $h$ aspirada* ${ }^{2}$. No cabe duda, pues, de que este dato ayudará no sólo a un mejor establecimiento de la etimología de dicha voz, por la luz que arroja sobre su procedencia geográfica y social, sino a entenderse así que con ella ha ocurrido seguramente similar proceso, en lo fonético y en lo ortográfico, al que tuvo lugar en elementos léxicos como jamelgo o juerga. Otra muestra de lo

40 Se trata del poema titulado «A una dama moza casada con un viejo», en el que se lee «un vieho de los diabos / que adora y no saquifica» y «ya en paharitos no tato, / que se los come la gata»: Luis de Góngora, Letrillas. Edición, introducción y notas de $\mathbf{R}$. Jammes, Madrid, Castalia, 1981, pág. 135.

41 Francisco de Quevedo, Obra poética, Edición de José Manuel Blecua, Madrid, Castalia, 1981, t. IV, pág. 203, vv. 289-297. El copista del manuscrito es andaluz, como con su habitual perspicacia indica el editor, pues escribe lus, reconoscas, condisión, lucitano, paresca, abrazado 'abrasado', junto a otros «errores» entre los que se cuenta la elisión de $-s$ final. A mi buen amigo Germán Colón debo la pista de este horoba.

$42 D E C H$, s. v. joroba. 
que en este terreno queda por hacer se ve en la grafía aufero 'agujero' que en el texto quevedesco de hacia 1624 titulado La polilla de Madrid ${ }^{43}$ parece remitir a una pronunciación velar de la $j$ a través de una simple equivalencia acústica esporádica, pero de ningún modo inusitada, o bien de la relación existente entre la /f/ y su aspiración, equivalencia acústica de tipo más particular, que en cierto modo implicaría a su vez el previo relajamiento articulatorio del fonema $/ x /$. El caso contrario, grafía $j$ por $f$ etimológica, se halla por dos veces en textos almerienses (Vera, 1569) con el nombre de persona Pedro Martínez de Ribajorada ${ }^{44}$.

En los primeros años del xvir los ejemplos de $h$ por $x, g, j$ se multiplican tanto en fuentes peninsulares como hispanoamericanas ${ }^{45}$, y no puede decirse que tal cosa ocurra sólo por motivos expresivos o estilísticos en la literatura, o como señal de incultura en escritos no literarios, sino que este cúmulo de hechos grafémicos es, antes que nada, el efecto visual de la incontenible expansión de nuevos modelos fonéticos en el mundo hispanohablante. Con la lógica gradación cuantitativa, la mencionada circunstancia lingüística aflorará en alternancias grafémicas como la que revela el doble arjentados-anhertados 'argentados (plateados)' de una redacción de Indias baja en caracterización sociocultural ${ }^{46}$, igual que la forma rrecohidamente 'recogidamente' del año 1609, que por tres veces se escribe así en texto de importante escribanía antillana, cuya elegante letra denota la autoría de un esmerado pendolista, esto al lado de la grafía inversa en un jecho por hecho (cf. § 3.2), lo que, sin embargo, no es óbice para que en dicho informe oficial se registre un seseo generalizado, además de "faltas» como otlas 'otras' y rública 'rúbrica' 47 . En Es-

43 Francisco DE QUEvedo, op. cit., t. IV, pág. 118, v. 291, donde viene «vuestro aufero» por «vuestro aujero» (vulgarismo en lugar de agujero). D. José Manuel Blecua había anotado ya esta forma como error (pág. 111). Puede haberse dado en este término el mismo procedimiento evolutivo que se observa en el aragonesismo tafugo 'tajugo (tejón)', mencionado en la nota 62.

44 Cf. N. Cabrillana, Documentos notariales referentes a los moriscos (1569-1571), Universidad de Granada, 1978, págs. 128-129. Entiendo que se trata del topónimo Ribaforada (< lat. ri p a for a t a m), que, por ejemplo, existe en la Ribera de Navarra, y ya se sabe que en las vecinas tierras murcianas hubo un fuerte componente de repoblación navarroaragonesa.

45 No pocos casos de dicha alternancia vienen citados en mi artículo «La fonética del español meridional y sus fuentes históricas».

46 Variación ortográfica que descubro en P. BoYD-Bowman, Léxico hispanoamericano del siglo XVI, s. v. zapato, pág. 1002: mejicanismo de 1550-56.

47 Escrito fechado en Santiago de Cuba, que trata de una reclamación económica de Juan de Góngora, presbitero y sacristán mayor de la catedral de esa ciudad: Archivo General de Indias (A.G.I.), Santo Domingo, Sección Audiencia, legajo 153, ramo IV, fols. $81-87$ (contados por una sola cara): rrecohidamente (fols. 81, 83, 84);

LXV, $3.0-4.0-8$ 
paña, Sebastián de Covarrubias incluirá en su diccionario referencias indirectas de lo mismo cuando escribe: "holgín, holgina, parece ser lo mesmo que jorgín y jorgina, hechizero y hechizera» ${ }^{48}$, y también cuando se aventura a relacionar etimológicamente erraj con la raíz hebrea, «o por mejor decir caldea», rahaha ${ }^{49}$. Antes, en la carta autógrafa que una monja onubense daba en Sevilla el 1596, junto a numerosas confusiones de la clase de dise 'dice' o quiçiera 'quisiera' y ciruamos 'sirvamos', se halla el onomástico hulián 'Julián', con $h$ por $j^{50}$.

3.2. Tal vez sean más frecuentes los casos de $x, g, j$ en lugar de $h$, de los que ya había dado a conocer éstos: un joya 'hoya' y el ultracorrecto jordenança 'hordenança (ordenanza)', ambos andaluces y del año 1479, el segundo de ellos de igual, o muy similar, causalidad que el jemisferio 'hemisferio' y el jabemos 'habemos' más arriba comentados ${ }^{51}$. De 1528 es el jiennense Xodar, que con el sentido de 'hoder, joder' ( < lat. f u t u e r e) aparece en La Lozana andaluza, de bien conocido autor meridional, y a xoderos 'cierto juego de naipes', ejemplo de idéntico tratamiento fonético sobre el mismo término verbal, se registraba en repartimiento malagueño de 1491, palabra que todavía pervive con ese significado en pueblos de Andalucía occidental, y en sitios tan distantes como Seseña (Toledo), en la expresión "jugar al jódete», o Buenos Aires, aquí con la variante xodéte 'burro (juego de cartas)' debida al voseo ${ }^{52}$. A los mencionados datos es preciso añadir el extremeño jau 'hao, hau' fechado en 1517 y

«se me a jecho rrelaçión» (fol. 82). Este documento está fechado el 14 de junio de 1609 en Santiago de Cuba y su redactor fue el escribano Gabriel de Santisteban.

48 Tesoro de la lengua castellana o española, 1611; reedición facsimilar, Madrid, Ed. Turner, 1977, s. v. holgado.

4 S. v. arraax.

so Carta escrita en la primera cara de un solo folio, perteneciente a la biblioteca particular de don Enrique Martín Arrayaz, de Valverde del Camino (Huelva). En un próximo trabajo editaré este texto integramente.

51 Véanse las notas 13 y 15 . Recordaré que jemisferio se encuentra en fuente andaluza de comienzos del XIx, mientras que jabemos se debe al madrileño Ramón de la Cruz, estando fechado en $\mathbf{1 7 8 0}$. Estoy seguro de que una exhaustiva búsqueda en fuentes literarias y en textos no literarios de los siglos XVI y XVII, sobre todo en los más teñidos de rasgos populares o vulgares, ha de proporcionar más datos del género para el esclarecimiento de esta cuestión histórica, como los del doblete huncia-juncia y la atestiguación de xambrino 'hambriento': José L. ALoNso HeRnánDEz, Léxico del marginalismo del Siglo de Oro, Universidad de Salamanca, 1977, páginas $445,467,789$.

52 Como se ve, este antiguo término del juego de naipes todavía parece tener una amplia difusión en el mundo hispanohablante, aunque se trate de localizaciones dispersas. La forma a xoderos ha sido verificada en el legajo 62, cuadernillo 36 , del Archivo de la Catedral de Málaga. El Dr. Antonio Garrido Moraga tuvo la amabilidad de fotocopiarme el texto en cuestion. 
comentado por María Josefa Canellada, así como los andalucismos moxarras 'moharras' y tarages 'tarahes', que documento en 1502-1503 y 1531, respectivamente ${ }^{53}$. Por otro lado, una nueva relección de La Lozana andaluza me ha permitido fijarme en la existencia de la forma injuina ( "putas ynjuynas» en la edición facsímil), que el editor interpreta como 'inguina, con bubas' y cuyo cambio de $j$ en lugar de $g$ tal vez pueda tomarse en apoyo del valor velar del topónimo incluido en el refrán «a la par, a la par lleguemos a Xodar» ${ }^{54}$.

Aparte de éstas que acabo de señalar, las nuevas aportaciones documentales para un futuro replanteamiento de este problema de fonología histórica se inician con un bujería del año 1528, a propósito del cual Corominas da las atestiguaciones bohonería 1480, bujería 'chuchería (especialmente las que se dan o se ceden en trueque a los indios y salvajes)' 1528, bugerias 1565, y afirma: «deformación del port. bufaría, nacida seguramente en las Indias, y comparable a las formas rujial 'rufián', jurioso 'furioso', junción, julano, projundo, etc., hoy usuales en gran parte de América y España ${ }^{55}$. Pero, por lo que a esta fechación respecta, me permito sugerir la idea de que, aunque el particular despojo textual pueda ser hispanoamericano, tal «deformación» fonética no debió surgir en el Nuevo Mundo, sino que hubo de ser llevada a él por colonizadores españoles, seguramente extremeños o andaluces occidentales, lo que evidencian simples razones cronológicas. $Y$, puesto que de las Indias se trata, un memorial eclesiástico de 1577 -de nivel nada inculto, por cierto- trae juiendo 'huyendo' ( "vase juiendo a la tierra firme») ${ }^{56}$; justamente medio siglo después, otra información de la misma Audiencia

53 En el Léxico hispanoamericano del siglo XVI de Boyd-Bowman encuentro un agogadero 'ahogadero' cubano de 1578-1585 (s. v., pág. 30).

54 Dicha pronunciación velar de la $x$ - inicial de Xódar, o Xodár, es necesaria para que el refrán tenga el sentido sexual que se le ha atribuido y que, sin duda, tiene. La grafía $j$ de injuina coincide en la edición que B. Damiani ha hecho de esta obra (Madrid, Clásicos Castalia, 1972, pág. 101), y en la facsímil de A. Pérez Gómez (Valencia, 1950, mamotreto XX). No se comprende muy bien, sin embargo, por qué Damiani ha puesto joder tres veces y enmojecerán (págs. 145, 146, 163, 203), cuando en el texto facsímil de Pérez Gómez pone hoder y enmohecerán (mamotretos XXXIII, XXXIV, XXXVIII, LIII). Por otro lado, en la primera edición figura un Herusalen 'Hieruselén, Jerusalén' (mamotreto LII) junto a Hierosolimitanos, pudiéndose reflejar la velar / $\mathbf{x}$ / en la primera de estas dos formas.

$55 D E C H$, s. v. buhonero. Como puede verse, ahora no le extraña a Corominas el cambio de $g, j$ por $h$, a diferencia de lo que, en el caso contrario (cambio de $h$ por $i$ ), le sucede a propósito de harpillera, y eso que entre una y otra documentación apenas median diecisiete años.

56 A.G.I., Santo Domingo, Sección Audiencia, legajo 96 de Cartas y expedientes de personas eclesiásticas, ramo I, fol. 17. En este texto se deslizan también las cacografías fiansas, nesçecidades y rresçide 'reside'. 
dominicana contiene repetida la grafía jasta 'hasta': "por esta causa no sité para haser aquesta ynformasión a el dicho señor fiscal, y no auer jasta agora nombrado fiscal en esta Real audiençia»; «desde estonses jasta oy están poblados» (a. 1627) ${ }^{57}$. Muy poco anterior, de 1609 , es el también americano jecho («se me a jecho») antes indicado (cf. § 3.1, nota 47).

3.3. La rapidez con que solían redactarse estos documentos (interrogatorios judiciales, peticiones e informes oficiales, memoriales, etc.), circunstancia que se hace bien visible en la manera de enlazarse las palabras con la letra procesal, explica en buena medida el acusado carácter fonético de la ortografía usual en muchos de ellos, lo que, vuelvo a insistir, no tiene por qué entenderse como hecho probatorio de una radical incultura del amanuense en cuestión, sobre todo si de lo que se trata es de equivocaciones esporádicas. Diferente resulta el caso de textos como el que en 1590 pergeñaba para la Casa de Contratación de Sevilla el escribano Álvaro de Salinas con - no hay que dejar de lado este detalle esencial - una caligrafía muy irregular: en él se trazó la grafía a gecho 'ha hecho' en diez ocasiones, en una gechas («diligensias gechas en este proçeso»), y en otra gagas 'hagas' ( gagas la conpetençia de los bancos»); sin embargo, otra mano ha intentado corregir estos «errores» -algún que otro ejemplo se le ha escapado al corrector, con todo- tachando con una o dos líneas inclinadas esa $g$ - inicial, y por una vez superponiéndole una $h$ que, no obstante, permite leer con toda claridad el signo anteriormente escrito ${ }^{58}$. Todo ello, aparte del aspecto sociolinguís-

57 A.G.I., Santo Domingo, Sección Audiencia, legajo 221, fols. 2v, 3r. Este documento ofrece, asimismo, el empleo casi generalizado de $s$ por $s s, c, z$. El uso de una $j$ por $h$ en formas como juiendo, jasta o jecho (con frecuencia gecho, cf. § 3.3) si revela de manera incuestionable la existencia del fonema $/ x /$, y no alternancias grafémicas como la que se da en el doblete pagen-pague de texto mejicano del año 1558 (A.G.I., Audiencia de Méjico, legajo 168, Ramo Secular, cuadernillo 15, carta 8, fols. 22-23), alternancia siempre posible en la ortografía castellana antigua, así como la de $g$ y $j$ ante /a, e, $i /$, que depende en buena medida de la tradición escolar, cuando no de acendradas costumbres personales. Asi, por ejemplo, la grafía riga 'rija' aparece invariablemente en la frase formularia final de los escritos del doctor Melgarejo, oficial de esa misma Audiencia de Méjico a mediados del siglo xvr.

58 A.G.I., Sección Indiferente General, legajo 2007, fols. $3 r$ y v, 12v, 13v, 14r, 19v, $22 \mathrm{r}$ y v. Se lee admogarifazgo 'almojarifazgo' en el fol. 16r. La corrección con $h$ está en el fol. 22v; en el fol. 13v el mismo enmendante ha anotado en el margen izquierdo, al lado de un «lo a gecho», lo a echo. Aquí se verifica el empleo de $g$ por $h$, contrario al que se comprueba en el rrecohidamente visto en la nota 47,0 al hente (xes hente de guerra y temida de los yndios») escrito en territorios del Río de la Plata el af́o 1581 por el franciscano Juan Pascual de Rivadeneyra, que -y ténganse muy en cuenta las precisiones geográfica y cronológica que siguen- había 
tico que suponen las mencionadas enmiendas, viene a indicar que dicho escribano mantenía la aspiración /h/ procedente del lat. /f-/, que realizaba mediante pronunciación velar los ant. $/ \check{s}, \check{z} /$, y que, si bien este último extremo no puede asegurarse rotundamente, en su idiolecto se igualaban ya $/ \mathrm{h} / \mathrm{y} / \mathrm{x} /$, por relajamiento articulatorio del segundo elemento fonológico.

Se ha visto cómo otro escribiente, posiblemente dotado de una formación escolar más depurada, se sintió obligado a rectificar un grafema que no estaba de acuerdo con los cánones ortográficos tradicionales. Y no estamos ante un hecho aislado, ni mucho menos, pues en otra parte he aducido el ejemplo granadino "para que vo lo digan", que en texto cancilleresco de 1550 se ve anulado y enmendado a continuación "para que vos lo digan" ${ }^{59}$; dos nuevos casos traeré a colación, ahora extraídos de protocolos sevillanos: el primero está fechado en 1533 y consiste en que el onomástico Rodrigues tiene una $z$ trazada sobre la caja de escritura, encima de la "ese sigma» que se escribió en primer lugar; el segundo lo proporciona otro protocolo notarial de 1534 en el que se había redactado la secuencia "las dichas condiçione y obligaziones", a la que con tinta distinta otra pluma añadió una ese alta ${ }^{60}$. $\mathrm{Ni}$ siquiera las fuentes literarias están libres de correcciones de este tipo, porque, por ejemplo, en la fe de erratas del Epicteto y Phocílides en español de Quevedo don José Manuel Blecua anota: "la $h$ de hacienda, enmendada a mano sobre letra que no se ve" ${ }^{61}$. El enmendante se encontró, tal vez, en situación similar a la de quien corrigió el sevillano gecho de 1590.

Es probable que la articulación velar fricativa sorda se halle indicada con la $x$ - del antropónimo turolense Pedro Xuesa que documento en $1606^{62}$. Ninguna dificultad presenta el joia 'hoya' que aparece repetido

nacido en Galicia en 1531: Marfa Beatriz Fontanella de Weinberg, Aspectos del español hablado en el Río de la Plata durante los siglos XVI y XVII, Bahía Blanca, 1982, pág. 16.

59. En mis «Materiales para la historia de la aspiración de la /-s/ implosiva en las hablas andaluzas», pág. 169.

60 El dato referente a la rectificación con $z$ sobre Rodrigues puede verse en el Archivo Histórico de Protocolos Notariales de Sevilla, Oficio XVI, notaría de la calle de Tundidores, legajo 1533, fol. 9 del cuadernillo primero; el segundo pertenece al Oficio VI, notaría de la Posada de la Parra, legajo 1534, protocolo del escribano Juan Núñez, de hacia la mitad del legajo, sin foliar.

61 Francisco de Quevedo, Obra poética, t. IV, pág. 478.

62 Cf. C. J. Wirturn, art. cit., pág. 215. Este nombre de persona figura en anotación al margen del manuscrito, con la fecha de referencia. Se trataría de la representación con $x$ del fonema velar $/ \mathrm{x} /$, por $/ \mathrm{h} /</ \mathrm{f} /$ etimológica (< lat. f b s s a m), o directamente a partir de /f/ romance: juina por fuina es frecuente en Aragón, también en las hablas turolenses, y Jumpudia ( $<$ f on t em putida m) es micro- 
en manuscrito pacense de 1601 editado por Rodríguez Moñino: «en el coso antiguo de la Armita para adelante allarás una sepultura piquena y a cinco pasos al poniente una joia argamasada»; "en el mesmo comaro una joia de Tixolas con argamasa cuberta de cantería» ${ }^{63}$. En el mismo corpus se descubre la forma ajiestada, sin duda variante prefijada de enhiestada (enhiesto < lat. In f e s t u m): "en el penedo ferrollo, cerrojo, en el mismo hecimos un dequarto y lo hinchimos de oro y plata y la pusimos encima una porta bien ajiestada con su felrollo, cerrojo, y enchombada con chombo y argamasa» ${ }^{64}$.

3.4. El precitado texto extremeño proporciona también la forma ajugereada 'agujereada' («hai una losa grande con una sartén echa a pico grande ajugereada por el medio del mango") ${ }^{65}$, que, evidentemente, puede deberse a un simple lapsus cálami producido por metátesis ortográfica, pero que igualmente cabe entenderla en sentido fonético. Sea como fuere, el hecho es que desde el momento en que se verifican intercambios de las grafías correspondientes a los ant. $/ \check{\zeta}, \check{z} /$ con los pertenecientes a los fonemas $/ \mathrm{g} / \mathrm{y} / \mathrm{k} /$, sobre todo con los del primero, hay que aceptar la vigencia de un nuevo fonema velar / $\mathrm{x} /$ que, junto a los dos ya existentes $/ \mathrm{g} / \mathrm{y} / \mathbf{k} /$, pasaba a constituir el triple haz de correlaciones de orden velar del sistema fonológico del español moderno. Era mucho más difícil, en efecto, la confusión de grafías de realizaciones fonéticas palatales con las de sonidos velares, y, por otro lado, esta serie de hechos grafémicos sólo se registra contemporáneamente a lo que se comenta en apartados precedentes, de manera que el fenómeno ahora apuntado se configura como una tercera perspectiva filológica del problema de fonología diacrónica concerniente a la mutación de $/ \check{\text { s }}$ ž/ en $/ \mathbf{x} /$.

Boyd-Bowman identificó un carto 'harto' - con documentación de la grafía $c$ de /k/ en lugar de la $h$, signo de /h/-, precisamente en una

topónimo del municipio zaragozano de Magallón. El caso fonético contrario se verifica en la forma tafugo 'tajugo (tejón)' usual en localidades del valle del Ebro. Posiblemente esté relacionado el antropónimo Xuesa con el nombre de lugar Huesa del Común de la provincia de Teruel; de todos modos, el territorio de esta demarcación provincial fue uno de los más tempranamente castellanizados del ámbito aragonés, y en él se halla el macrotopónimo Jorcas, que parece remitir a un Horcas anterior (< Forcas < lat. $\mathrm{fu}$ r ca s).

63 A. R. Rodrfguez Monino, Los tesoros escondidos. Pelos y señales para encontrarlos, según un curioso manuscrito de 1601, Badajoz, 1942, pág. 30.

ot Ibidem, pág. 31. A. Viudas Camarasa señala como voz extremeña enhiehtalse 'ponerse de pie': Diccionario extremeño, Cáceres, 1980, s. v.

65 A. R. RodRfguez MoNino, op. cit., pág. 38. En el mismo manuscrito aparecen las formas bujero 'agujero' y abujerado 'agujerado' (págs. 38, 39). 
carta, enviada el año 1568 desde la Nueva España por el emigrado sevillano Antonio de Aguilar, en la que junto a este carto hay numerosos errores del tipo de gecho 'hecho', gasta 'hasta', garta 'harta', etc. ${ }^{66}$. A mi vez, hallo empleos de $j$ por $g$, grafía de $/ g /$, en dos pasajes de un texto andaluz oriental de 1490, concretamente en los nombres de persona Juzmán 'Guzmán' ["Gonçalo de Juzman (sic), regidor»], y Briueja 'Brihuega', topónimo con valor de apellido ${ }^{67}$. Y en memorial escrito en 1613 por un clérigo de la catedral de Santiago de Cuba, en el que se defendía de la acusación de judaizante de que había sido objeto, se lee con toda nitidez sanctiajo 'Santiago': «Antonio Sánchez de Moya, canónigo nombrado de la santa yglesia de sanctiajo de Cuba..." ${ }^{68}$.

Está también el uso del grafema $g u$, habitualmente utilizado para representar a /g/ ante /e, i/, en sustitución de los que durante la Edad Media fueron propios del prepalatal / $\check{z} /$, lo que, a mi modo de ver las cosas, significa, asimismo, que era su descendiente / $x /$ el envuelto en semejante vacilación ortográfica. Este procedimiento anómalo se verifica en un breve documento dado el año 1686 en el Consejo de Indias, donde hay dos casos de religuioso y uno de religuión ${ }^{69}$, y lo interesante de estas atestiguaciones es que se fijan en una sincronía que, esto nadie lo discute ya, era de general implantación del fonema / $\mathbf{x}$ / en español. A propósito de uno de los textos mejicanos de 1523 estudiados por Claudia Parodi de Teresa, dice esta autora: "Suele afirmarse que, a finales del siglo XVI, las sibilantes prepalatales $j-g$ y $x$ ya se habían velarizado. He encontrado, como posible muestra del inicio del atrasamiento articulatorio, en el manuscrito de Orduña, alternancia de las grafías origuinal, tres veces, frente a original, dos veces. Casos éstos, en que la confusión ortográfica podría reflejar una vacilación fonética» ${ }^{70}$. Pero este origuinal, en el contexto de todo lo que antecede, remite no al inicio de la retracción articulatoria, sino a una pronunciación plenamente velar. No se agotan los ejemplos de ello en los mencionados hasta ahora, pues en documentos aragoneses del XVI he despojado los dobletes tigeras-tigueras

66 P. BOYD-BOWMAN, art. cit., págs. 2-6.

67 M. Acién Almansa, op. cit., págs. 285, 369.

68 A.G.I., Santo Domingo, Sección Audiencia, legajo 153, fol. 86v del ramo IV.

69 A.G.I., Audiencia de Guadalajara, legajo 4, fol. 230r. Debo manifestar mi agradecimiento a doña María del Consuelo Gil Arrando por haberme facilitado el folio en el que figura este dato.

70 Claudia Parodi de Teresa, «Para el conocimiento de la fonética castellana en la Nueva España: 1523. Las sibilantes», Actas del III Congreso de la Asociación de Lingüística y de Filología de la América Latina, Universidad de Puerto Rico, 1976, página 119. Indica Claudia Parodi que este Francisco de Orduña era vizcaino. 
y algez-alguez (a. 1587) ${ }^{71}$, además de las grafías recoguida 'recogida' y leguitimamente 'legítimamente' (a. 1592) ${ }^{72}$, con la particularidad de que todos estos casos han sido convenientemente cotejados en los manuscritos originales que les corresponden del Archivo de Protocolos Notariales de Zaragoza.

3.5. J. L. Pensado ha manejado documentaciones en cierto modo similares a las que acabo de reseñar, como sustentación de su planteamiento histórico de la "gueada» y de la "geada» gallegas: un testijos 'testigos' de 1485, que Pensado no quiere usar por venir en copia de finales del xvir, un religuión 'religión' de 1699, el doblete Aranguez-Aranques 'Aranjuez' y la grafía venzego 'vencejo', en 1721, con muchos más ejemplos de fechas posteriores ${ }^{73}$. No son del todo equiparables, sin embargo, estos testimonios y los que yo he señalado, porque la causalidad y el sentido lingüístico de unos y otros tampoco son los mismos.

Del fenómeno noroccidental afirma el citado investigador: «como el gallego no tenía ningún fonema parecido en su inventario fonemático, se vio obligado a buscar las realizaciones más semejantes, y éstas fueron las de la /g/ y /k/ de su propio sistema " ${ }^{74}$. Sin descartar por completo alguna posible confusión fonética del moderno / $\mathrm{x} /$ con los preexistentes /g/ y / $/$ / en el espacio hispánico al que dedico este trabajo, pienso que éstas hubieron de ser sumamente aisladas, pues, contra lo que pasa en zonas gallegas, no han quedado huellas consistentes de ello ${ }^{75}$. Por consiguiente, las atestiguaciones que aquí doy de $j$ por $g$ (grafía de $/ g /$ ) y de gu por $g, j$ (grafías de $/ \mathbf{x} /$ ) con toda probabilidad son en su mayoría meras alternancias grafémicas provocadas por la difusión que estaba cobrando un fonema antes desconocido, pero que forzosamente debía grafiarse con los signos ortográficos tradicionalmente usados para las

71 A. SAN VICENTE, op. cit., doc. 33, pág. 180, para el primer doblete (algez-alguez arag. 'yeso' < lat. g $¥ \mathrm{p} \mathrm{s} \mathrm{u} \mathrm{m);} \mathrm{doc.} 35$, pág. 184 para el segundo.

72 Ibidem, doc. 60 , págs. 236-237.

73 J. L. Pensado y C. Prnsado Ruiz, «Gueada» y «geada» gallegas, Anejo XXI de Verba, Santiago de Compostela, 1983, págs. 22-26.

74 Ibidem, pág. 33.

75 Sólo en zonas relativamente próximas a Galicia se encuentran esporádicos ejemplos léxicos que reflejan un fenómeno fonético similar al hecho galaico ya comentado, y aun así algunos de ellos admiten otra explicación diferente: J. L. PENsado, op. cit., págs. 36, 70. De todos modos, nada de particular tiene que en la época en que se estaba produciendo la sustitución del viejo sistema fonológico por el nuevo tuvieran lugar diversas confusiones fonéticas, luego lexicalizadas por lo general, entre los elementos fonemáticos implicados en el cambio, así en las variantes injiestos-infiestos-inciestos 'enhiestos (pieza del carro)' que se registran en localidades salmantinas (DECH, s. v. enhiesto), o en las aragonesas ginestra-chineta-cinestrafinestra 'jineta (mamifero)' recogidas en el ALEANR (mapa 474). 
unidades fonemáticas en las que éste $/ \mathbf{x} /$ se había originado $(</ \check{\text { š }}, \check{z} /$ ). $Y$ es lógico que desde la aparición del fonema velar fricativo sordo el hablante, y también quien escribía, pasara a relacionarlo de alguna manera lo mismo con /h/, allá donde la aspiración de /f/ se mantenía, que, si bien en medida mucho menor, con $/ g / y / k /$. La diferencia fundamental estriba en el hecho de que mientras en el caso gallego se trata de la acomodación de un fonema que faltaba en su sistema consonántico, el problema que a mí me ocupa es el de la propagación geográfica y social de un particular cambio lingüístico en el mismo ámbito en que había surgido, que no es otro que el del castellano-español tomado en su conjunto.

Como se ve, todavía está muy extendida la idea de que el nacimiento del fonema $/ x$ / se dio en fechas tardías, en los años finales del siglo Xvi, y no digamos nada de su generalización normativa, aspecto que ni siquiera suele tocarse en los estudios al uso. No resulta extraño, así, que J. L. Pensado crea que en el aragonés Juan Pablo Bonet (con referencia cronológica del año 1620) aún no se descubre la existencia de la pronunciación velar ${ }^{76}$, opinión no compartida por otros autores, lo que, en definitiva, demuestra lo difícil que es sacar conclusiones válidas del exclusivo análisis de tratadistas de la época. Ahora bien, debe decirse con rotundidad que la cuestión cronológica condiciona el planteamiento, correcto o incorrecto, del cambio de un sistema consonántico por otro en su doble dimensión sociológica y dialectal. En este sentido, Pensado habla de la "recepción" de la /x/ en espacios no castellanos, entre los que menciona Andalucía y Aragón $\pi$, no obstante lo cual las documentaciones meridionales arriba aducidas prueban que la mutación $/ \check{\mathbf{s}}, \check{z} />/ \mathbf{x}$ / fue en el Sur autóctona, y nunca resultado de su propagación a partir de hablas de la Castilla norteña y central. En cuanto a Aragón, a lo largo del XV se consuma la castellanización de la mayor parte de su territorio y el proceso se acelera en la primera mitad de la centuria siguiente, de tal manera que el español regional allí configurado evoluciona con parecidas pautas a las que se observan en el resto del dominio castellanoespañol, salvo, claro está, en lo concerniente a la específica solución andaluza del par fonológico medieval / $\hat{\mathbf{s}}, \hat{z} /$ y en lo que atañe a tendencias de relajamientos consonánticos.

Que las cosas ocurrieron así se evidencia con la verificación de que muchas palabras del antiguo dialecto aragonés que tenían en sus étimos un grupo latinos $\dot{c}$, de tratamiento dialectal / $\$$ / frente al correspondien-

76 J. L. Pensado, op. cit., pág. 16.

7 J. L. PEnsado, op. cit., pág. 72. 
te resultado $/ \hat{\mathbf{s}} /$ del castellano medieval, no fueron sustituidas por los términos equivalentes de la lengua oficial $y$, sin embargo, en el curso del reajuste fonológico se comportaron igual que los castellanismos fonéticos. A esta especie histórica pertenecen, por ejemplo, las voces aragonesas ajada, faja, fajo, pajentar, rujiar (con /š/ originario), que son de etimologías idénticas a las palabras castellanas azada, haza, haz, pacentar, rociar.

4. Diversas son las consideraciones que de lo dicho se desprenden, como rica en implicaciones tanto estructurales como sociolinguísticas y dialectológicas es, asimismo, la serie de cambios fonológicos en cuestión. Por lo demás, tal vez pueda tomarse el tratamiento documental que aquí doy como piedra de toque para extender sus principios metodológicos - nunca excluyentes, ni en principio sujetos a una determinada postura teórica - a la totalidad del reajuste consonántico del español moderno y a otras grandes innovaciones fonéticas que en la época se desarrollaron por amplias áreas hispánicas, como son el yeísmo, el debilitamiento y aspiración de la /-s/ implosiva o la constitución del español de América en su nivel fónico. Esto, naturalmente, si se comprueba que los hallazgos así obtenidos suponen algún avance importante en el conocimiento científico del asunto encarado, interrogante cuya respuesta dejo al discernimiento del crítico lector.

4.1. Pero, anticipada esta idea, es razonable afirmar que no hay muchas posibilidades de hacer fonología diacrónica si no es acudiendo al despojo de fuentes fidedignas, a la vez que diversificadas diastrática y diatópicamente. Ello, claro está, si se quiere construir una verdadera historia de la lengua, como la historia que se practica en otras ciencias, y no meros edificios teóricos sólo apoyados en una operación mental más o menos complicada, más o menos sugestiva, pero de resultado hipotético por definición; y esto no significa, en absoluto, que en diacronía no tenga cabida la especulación, lo mismo para la descripción de los hechos fonológicos que para su explicación, ni que esté vedada la reconstrucción simplemente comparativa. Lo que quiere decirse es, sencillamente, que si una lengua, o dialecto, ha tenido cultivo escrito en el pasado, la fundamentación documental debe ser primordial en tal caso.

Por descontado, cada cual es libre de seguir el criterio que más adecuado le parezca para el logro de un mejor conocimiento diacrónico de la lengua; pero no está de más insistir en la obviedad de que es mucho más fiable la doctrina levantada sobre el sólido cimiento de lo que los 
textos aseguran, que no las teorías basadas en la sola elucubración mental, prestas a ser arrumbadas por el más inocente de los contrastes documentales. Y, en conclusión, si la historia del léxico, o la de la morfosintaxis, no se concibe sin un depurado y exhaustivo aparato de despojos textuales, que siempre se tiene por insuficiente, ¿qué razón hay para que en fonología diacrónica las cosas se entiendan de otra manera? ¿No será porque la práctica ha demostrado que es más cómodo establecer con ciertos visos de "verosimilitud" estructuras y encadenamientos evolutivos en unos pocos elementos fonemáticos, que en el inabarcable campo de las palabras?

4.2. En relación con lo últimamente expuesto, es preciso hacer hincapié sobre la necesidad de que la documentación analizada sea todo lo completa que lograrse pueda, a sabiendas de que la meta ideal es aquí muy difícil de alcanzar. Los textos aljamiado-moriscos constituyen en este aspecto una faceta historiográfica de inapreciable interés para el estudioso del español de los siglos XV y XVI, en particular por lo que al reajuste fonológico concierne; semejante valor, aunque en menor grado, tienen los escritos en alfabeto romance referidos a la minoría mudéjar. Algunos anticipos de lo que en este terreno es posible conseguir, en orden a obtener precisas fijaciones cronológicas y espaciales de determinados cambios fonéticos, se ofrecen en anteriores trabajos míos. Pero de las mencionadas fuentes los datos afloran a cada paso, conforme van siendo puestos ante la consideración del investigador. Un ejemplo más de ello que ahora puedo aportar es la alternancia entre $h$ y $j$ que se verifica en las variantes toponímicas alpujarreñas, fechadas en el año 1527, Handac alhajuza-Handac alfahuza ${ }^{78}$, con similar doblete grafémico al que se registra en los topónimos malagueños, datados en 14.92, Handahudy y Gandasala, que poseen el mismo formante léxico que los nombres de lugar precedentes ${ }^{79}$. Confusión entre $q$ y $h$ se atestigua en documentos almerienses de 1569 y 1570 relativos a los moriscos de las Alpujarras, a propósito del actual nombre de Quijillana, localidad de la provincia de Almería, que se ve grafiado una vez Quiciliana y en la segunda ocasión Heciliana ${ }^{80}$.

78 Cf. Juan Martinez Ruiz, «El topónimo Jandaq en las tahas de Ferreyra, Poqueyra y Xubiles en 1527», RFE, LXII, 1982, pág. 78.

79 Recogidos en mi artículo «El reajuste fonológico del español moderno en su preciso contexto histórico: sobre la evolución $/ \xi, \Sigma />/ x / n$, pág. 229. También aduzco aquí un aljadí (< ár. haddād) del Cancionero de Pedro del Pozo (1547), y los granadinos farha-farja (entre 1553 y 1568), Hayar-Jayar-Xayar (1565-1569).

80 Cf. N. Cabrillana, Documentos notariales referentes a los moriscos (1569-1571), 
4.3. No queda más remedio que afirmar sin ambages que la fonología diacrónica del español se ha construido sobre una insuficiente información filológica - la que con ímprobos esfuerzos reunió casi solo el malogrado A. Alonso-, circunstancia que aconseja su replanteamiento. En efecto, el descubrimiento de noticias documentales que contradicen diversos e importantes puntos de los esquemas fonológicos acuñados por lingüistas tan eminentes como A. Martinet y E. Alarcos Llorach -y cito únicamente a dos de los investigadores que más se han significado en el tratamiento de este problema histórico- debe invitar a la búsqueda de más datos que reafirmen lo que ya es tradición linguiística, o que, por el contrario, posibiliten una rectificación cuyo alcance la misma realidad de los hechos se encargará de precisar. Y conste, en honor de la verdad, que no soy el primero en advertir la deficiencia histórica con que se ha formulado la doctrina del reajuste fonológico del español moderno; otras plumas, más autorizadas sin duda que la mía, han instado a avanzar más allá de la labor filológica llevada a cabo por A. Alonso y que desgraciadamente quedó inacabada, y otros hispanistas han contribuido a mejorar notablemente la cronología de determinados fenómenos, en particular los de yeísmo y seseo, con dataciones muy anteriores a las que hasta no hace mucho se tenían por casi definitivas. Todo esto habrá que llevarlo, pues, a sus últimas consecuencias, porque la ciencia no quiere saber nada con inmovilismos acomodaticios ni con mentalidades acríticas.

4.4. Por consiguiente, no es un asunto baladí, ni mucho menos, el de la exactitud cronológica con que necesariamente ha de entenderse el complejo cambio linguístico al que pertenece la mutación $/ \grave{s}, \grave{z} />/ x /$, so pena de que permanezcan en una penumbra acientífica decisivos aspectos del engranaje estructural y sociológico en que se explica; y es indudable que tal exactitud se verá favorecida por el manejo de una adecuada documentación. La que hasta ahora yo he usado me mueve a expresar las siguientes observaciones, que dejo todavía como provisionales y sujetas a la corroboración de un aparato histórico que espero sea aún más consistente en un próximo futuro.

4.4.1. En primer lugar, la atestiguación de la pronunciación velar en Andalucía ya en el último tercio del siglo $\mathrm{xv}$, descontando las fechas de nacimiento de quienes cometieron las faltas ortográficas que la delatan,

Universidad de Granada, 1978, págs. 40, 164. Las dos formas van acompañadas de un corroborador sic. 
es un hecho que contradice la pretendida procedencia norteña de esta innovación lingüística, que, de haber tenido semejante procedencia geográfica, hubo de moverse necesariamente con mucha lentitud por el mapa de España, de manera que la presencia del fonema / $x$ / en las hablas de Castilla la Vieja adquiriría así una cronología impensablemente temprana.

4.4.2. En segundo lugar, esto quitaría validez a la pretendida causalidad de un sustrato común al eusquera, o semejante, influencia que sobre todo, pero no exclusivamente, se ha esgrimido para explicar la pérdida del rasgo opositivo sordez / sonoridad en las sibilantes medievales $/ \grave{s}, \hat{\mathbf{s}}, \mathbf{s} / \sim / \check{z}, \hat{z}, \mathrm{z} /$ del sistema "cantábrico» ${ }^{81}$. Y, en consecuencia, de nuevo sería insostenible la tesis de que el reajuste fonológico se produjera antes que en ninguna otra parte en la Castilla más norteña, de donde se habría difundido paulatinamente hacia el Centro, primero, y hasta el Sur, después.

4.4.3. En tercer lugar, tampoco parece cierto que la velarización de los antiguos / $\zeta, \grave{z} /$ haya sido un fenómeno verificado más tardíamente que otros del reajuste fonológico. Por el contrario, la información documental ya disponible para el esclarecimiento no sólo de esta concreta cuestión (la del paso de $/ \breve{s}, \grave{z} /$ a $/ \mathbf{x} /$ ), sino de todo el problema diacrónico de que forma parte, me induce a pensar que el conjunto de las alteraciones fonéticas experimentadas por los tres pares fonemáticos de referencia ocurrió sin escalonamientos cronológicos tan sensibles como los que se han propuesto. En mi opinión, el cambio que afectó a esas seis sibilantes se desarrollo inicialmente en un medio popular, tal vez connotado de vulgarismo al principio, pero de manera casi simultánea en muy distintos puntos de la geografía española, lo mismo en el ámbito estrictamente castellano que en los espacios castellanizados de León y de Aragón, o que en Andalucía, la Novísima Castilla, sólo que aquí con su particular solución de / $\hat{s}, \hat{z}, s, z /$ en el ceceo-seseo. Por esa época estaban también en auge en amplias áreas peninsulares las grandes trans-

81 E. Alarcos Llorach utiliza la expresión «sistema cantábrico» en su Fonología española, pág. 270, y se apoya para ello en la doctrina de A. Martinet. Sostiene también el investigador español que la velarización de las antiguas palatales / $\mathbf{s}, \mathbf{z} /$ es un fenómeno tardío, mucho más que el de la igualación de $s / z, 8 / \hat{z}$ y $\xi / z$ en beneficio de las unidades sordas, contexto general de pérdida de la sonoridad ocurrida en zonas norteñas al que pertenecería igualmente, a pesar de sus conocidas particularidades, el cambio $/ \xi, \grave{z} />/ x /$ (ibidem, págs. 271-272). 
formaciones fonéticas concernientes a la /-s/ implosiva y a la oposición $/ \mathrm{l} / \sim / \mathrm{y} /$, que se creían mucho más recientes ${ }^{82}$.

4.4.4. En definitiva, no concibo el reajuste fonológico del español moderno más que como un movimiento de reestructuración lingüística surgido y expandido a lo largo y a lo ancho de todo el territorio castellano-español, sin grandes hiatos cronológicos ni en lo que toca a las varias mutaciones fonemáticas implicadas en el proceso general, ni en lo que atañe a su difusión geográfica. Al menos habría que considerar la existencia de diversos focos irradiadores del cambio, desde los cuales se producía la asimilación social en una marcha siempre ascendente a partir de los niveles inferiores de la comunidad de hablantes, hasta alcanzar los estratos más puristas y refractarios a la innovación. Por lo demás, este enfoque sincronizado de tan fundamental reajuste fonológico es incluso muy coherente desde el punto de vista estructural, pues de otro modo sería necesario acabar planteándose qué pudo ocurrir con el sistema, o con los sistemas, intermedio entre el del castellano medieval y el de la lengua moderna, problema del que nadie se ha ocupado hasta el momento.

5. Queda mucha tarea por delante hasta que podamos disponer de las precisas claves del reajuste consonántico del castellano medieval en lo que al desarrollo de su difusión geográfica y sociocultural concierne. En esta investigación tampoco se ha arrojado luz definitiva sobre el particular cambio de $/ \zeta, \grave{z} /$ en $/ x /$, aunque tal vez se hayan dado pasos efectivos hacia su mejor comprensión histórica, que, al mismo tiempo, ejemplifica la necesidad de un nuevo enfoque, más rico en información documental, para el conjunto de transformaciones fonológicas al que la velarización de antiguos fonemas palatales pertenece.

En este sentido, es obvio que cuanto mayor sea la amplitud y variedad de los datos manejados tanto más fácil será dar al problema de diacronía lingüística una solución auténticamente veraz y coherente. Así, por ejemplo, el que don Ramón de la Cruz emplee con cierta frecuencia en sus sainetes la grafía $j$ en lugar de una $h$ signo de aspiración (cf. n. 15), se cohonesta con el hecho de que por entonces ocurriera lo propio en escrito dado el año 1763 en una localidad sevillana ( sitio del Cañuelo y

82 Por supuesto, simplificaciones de las antiguas sibilantes / , 2, s, z/ similares a las ocurridas en Andalucía se han dado también en otros puntos de España, pero siempre con carácter local o, a lo sumo, comarcal, en ocasiones con soluciones de un marcado carácter arcaizante. Para uno de estos casos, véase D. CataláN, «Concepto linguístico del dialecto chinato en un chinato-hablante», RDTP, X, 1954, págs. $10-28$. 
juente de la queba») ${ }^{83}$, o en padrones rurales del Río de la Plata, con un Jurtado 'Hurtado' y un Jormigo 'Hormigo' de 1738 y 1778, respectivamente $^{84}$. Ya en la centuria anterior un autor literario como Gracián corrobora en su Criticón lo que indicaban las voces con grafema gu por $x, g, j$ verificadas en protocolos zaragozanos de finales del xvi (cf. ns. 71, 72). Efectivamente, en las primeras ediciones de esta obra se registra un caso de hota 'gota (enfermedad)' que o salió así de la pluma del jesuita aragonés, o se debe a uno de los impresores ${ }^{85}$. De todos modos, en El Criticón se descubre un juego semántico entre horcas y ajorcas que sólo su semejanza fonética podía permitir: «Estavan persuadiendo a una hermosa muger que la enriquecían y engalanavan, y echávanla al cuello una cadena de una esclavitud de por vida y aun por muerte, la argolla de un rico collar, las esposas de unos preciosos braçaletes que paran en ajorcas» ${ }^{86}$.

Es muy posible que Gracián estuviera recurriendo al conocimiento del castellano toledano que había adquirido durante los años juveniles que pasó en la ciudad imperial, de la misma manera que acude al tópico acuñado por la literatura de la época cuando escribe: "Pero no, sino aquel que habla aspirando, que parece se traga los hombres quando

83 Archivo municipal de Guadalcanal, Libro de Protocolos CXL, fol. 46. En las mismas fuentes municipales se halla un dejesa 'dehesa' del año 1686: "Dejesa del postigo (Libro de Protocolos LXV, fol. 23). La zona de la Sierra Norte de Sevilla en la que se halla enclavado Guadalcanal todavía mantiene muy viva la aspiración de /f-/, lo que se manifiesta en la frase de identificación comarcal "el que no diga jacha, jigo y jiguera, no es de mi tierra».

84 M.॰ Beatriz Fontanella de Weinberg, El español bonaerense en el siglo XVIII, Bahía Blanca, 1984, pág. 42. Estos hechos, y los de la nota precedente, demuestran que desde el momento en que la aspiración de /f-/ dejo de usarse entre los cultos, que en la escritura la representaban con $h$, ya no se pudo darle otros signos ortográficos que $g, j$.

85 Baltasar Gracián, El Criticón, edición de M. Romera Navarro, Filadelfia, 19381940, t. I, pág. 331 y nota 79. Desde la primera edición de 1651 se verifica hota hasta la de 1748, a partir de la cual se pone ya gota, palabra que también aparece con grafía $g$ - en la ed. príncipe (t. III, pág. 354), de la que, sin embargo, no se conserva el texto autógrafo. De todos modos, es la existencia del haz de correlaciones velar $/ \mathbf{k}, \mathrm{g}, \mathrm{x} / \mathrm{lo}$ que permite este tipo de confusiones ortográficas, intencionadas unas veces $\mathrm{e}$ inconscientes otras, como, igualmente, las señaladas en las notas 69-72, en ocasiones con la ayuda de la aspiración /h/ de /f-/, que se cruza en la conciencia del hablante con alguno de los fonemas velares, sobre todo, lógicamente, con $/ \mathbf{x} /$, lo que, seguramente como mero recurso literario, puede haberse dado en la forma gracianesca. Ningún artificio debió de mediar en el aufero 'agujero' más arriba aducido (cf. n. 43), ni en el argentino fustificación 'justificación', que Fontanella de Weinberg documenta en 1804 (op. cit., pág. 42).

86 Baltasar Gracian, El Criticón, t. II, pág. 115 y n. 200. Esta es la explicación que da Romera, quien advierte que en la edición de 1773 se cambió ajorcas por horca. 
alienta» ${ }^{87}$. Y conscientemente pone $g$ por $h$ en otro pasaje sumamente aleccionador: "Atendieron y oyeron que el primero dezía fillo, el segundo fijo, el tercero hijo, y [el] quarto ya dezía gixo a lo andaluz» ${ }^{88}$. Pues bien, pasando por alto la cuestión de si sería aspirada o fricativa la pronunciación de esa $g$ - inicial, y lo discutible del exclusivismo dialectal que se le propone, lo cierto es que dicha grafía está representando al moderno fonema velar $/ x /$, sin ningún género de duda también existente por entonces en el español regional de Aragón, y desde mucho antes. No es menos cierto que si $g$ - simboliza a $/ \mathbf{x} /$, otro tanto tiene que ocurrir con la - $x$ - intervocálica, donde ya no hay forma de pensar en un particularismo fonético meridional, sino en un hecho que remite a la lengua común. Por lo demás, esta palabra reaparecerá con carácter tópico poco después, en villancico zaragozano del año 1675, puesta en boca de un imaginario personaje andaluz:

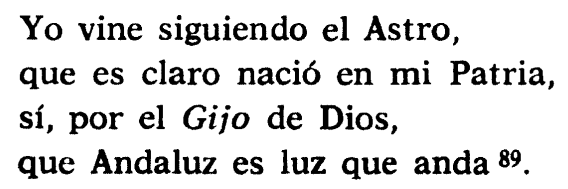

Juan A. Frago Gracia

87 Baltasar Gracian, El Criticón, t. I, pág. 302.

88 Baltasar Gracian, El Criticón, t. III, pág. 322.

89 Lyra poética de Vicente Sánchez, natural de la Imperial Ciudad de Zaragoza. Obras pósthumas que saca a la luz un aficionado al autor, Zaragoza, Manuel Román, 1688: villancico IX de los que se cantaron en el Pilar ese año (págs. 286-287). Este libro se conserva en la Biblioteca Universitaria de Zaragoza. 